H. Gyasi MB BS FFARCSI,

A. Williams MB BS, FFARCS,

C. Melloni MD, D.R. Bevan MB MRCP FFARCs

\title{
ORG NC45 for short intra-abdominal operations: a comparison with succinylcholine
}

ORG NC45 was compared with succinylcholine to produce muscle relaxation for short, intra-abdominal operations in 40 patients during nitrous oxide-oxygenenflurane anaesthesia. Intubating conditions after ORG NC45, $100 \mu \mathrm{g} / \mathrm{kg}$, were similar to those after succinylcholine I $\mathrm{mg} / \mathrm{kg}$, although this was achieved at a mean rime of $229.9 \pm 10.8 \mathrm{sec}$ compared with $129.8 \pm$ $14.2 \mathrm{sec}$ after succinylcholine. Muscle relaxation during surgery, mean duration 32.5 minutes, was provided in the succinylcholine group with an infusion and in the ORG NC45 group by repeated boluses, $10 \mu \mathrm{g} / \mathrm{kg}$, which were required in four patients. At the end of surgery $O R G$ NC45 was antogonized with atropine, $17 \mathrm{\mu g} / \mathrm{kg}$, and neostigmine, $36 \mu \mathrm{g} / \mathrm{kg}$, which were repeated in two patients. Postoperative recovery of neuromuscular function was indistinguishable between the two groups. We conclude that ORG NC45 is a suitable relaxant for short, intra-abdominal operations if sufficient time, three to four minutes, is allowed to produce good intubating conditions.

Key words NEUROMUSCULAR RELAXANTS: succinylcholine, ORG NC45.

From the Departments of Anaesthesia, Royal Victoria Hospital and McGill University.

Address correspondence to: Dr. D.R. Bevan, Department of Anaesthesia, Royal Victoria Hospital, 687 Pine Avenue West, Montréal, Québec H3A 1A1.
ORG NC45 (Norcuron) is a monoquaternary analogue of pancuronium which is undergoing clinical trial in North America. It has been shown to be faster in onset, of shorter duration and more readily antagonized by neostigmine than pancuronium, ${ }^{1-3}$ and has the additional advantage of cardiovascular stability. ${ }^{4}$ Such properties suggest it might be ideal for operations of short duration, 30 minutes or less, requiring profound muscle relaxation. In this centre such operations are usually performed using a succinylcholine infusion although the disadvantages of succinylcholine are well documented; increases in serum potassium concentration, intraocular pressure, and intra-gastric pressure, phase II neuromuscular block, muscle fasciculations and postoperative muscle pain. ${ }^{5}$ Other studie $s^{1,3}$ have compared ORG NC45 with longer acting nondepolarizing drugs, which would be inappropriate for short procedures, but no direct comparisons with succinylcholine have been reported.

Previous experience with ORG NC45 $5^{6,7}$ suggested that doses of less than $90 \mu \mathrm{g} / \mathrm{kg}$ were unlikely to provide reliable intubating conditions within less than 3 minutes, while doses much greater than this might produce intense neuromuscular block for longer than 30 minutes.

The present study was designed to compare ORG $\mathrm{NC45}$, in an initial dose of $100 \mu \mathrm{g} / \mathrm{kg}$, with an infusion of succinylcholine in women undergoing laparoscopic procedures. In this clinical study, the usual nitrous oxide-oxygen-enflurane succinylcholine sequence was altered only by the substitution of ORG NC45 for succinylcholine. Comparisons were made of the times to complete neuromuscular block, intubating conditions and recovery of neuromuscular activity at the end of surgery but 
TABLE I Neuromuscular blocking drug regimens

\begin{tabular}{llllllr}
\hline & & & & & Anaesthesia \\
duration \\
Group & Intubation & $\begin{array}{l}\text { Mainteriance of } \\
\text { neuromuscular blockade }\end{array}$ & $\begin{array}{l}\text { Age } \\
(\mathrm{y})\end{array}$ & $\begin{array}{l}\text { Weight } \\
(\mathrm{kg})\end{array}$ & $\begin{array}{l}\text { Toraldose } \\
(\mathrm{mg})\end{array}$ \\
\hline Control & Succinylcholine & Succinylcholine infusion & 32.1 & 54.5 & 32.1 & 216.6 \\
& $1.5 \mathrm{mg} / \mathrm{kg}$ & $1 \mathrm{mg} / \mathrm{ml}$ & \pm 1.1 & \pm 1.33 & \pm 1.9 & \pm 11.4 \\
Study & ORG NC45 & ORG NC45 & 34.0 & 57.1 & 33.0 & 5.8 \\
& $100 \mu \mathrm{g} / \mathrm{kg}$ & $10 \mu \mathrm{mg}$ as required & \pm 1.5 & \pm 1.7 & \pm 3.0 & \pm 0.2 \\
\hline
\end{tabular}

TABLE II Scoring of intubating conditions (after Fahey et al. ${ }^{3}$ )

\begin{tabular}{ll}
\hline Score & Conditions \\
\hline 0 & $\begin{array}{c}\text { Cords abducted, good visualization, no patient } \\
\text { movement }\end{array}$ \\
1 & $\begin{array}{c}\text { Cords abudcted, good visualization, diaphragrnatic } \\
\text { movement with intubation }\end{array}$ \\
2 & $\begin{array}{c}\text { Cords slightly abducted, fair visualization, coughing } \\
\text { with intubation }\end{array}$ \\
3 & $\begin{array}{c}\text { Cords moderately abducted, poor visualization, } \\
\text { gross body movement with intubation }\end{array}$ \\
\hline
\end{tabular}

utilizing only commonly available monitoring equipment.

\section{Methods}

The protocol was approved by the Hospital Ethics Committee and informed, written consent obtained from 40 healthy adult women, ASA physical status I, with no known neuromuscular, renal or hepatic disorders, electrolyte imbalance, and who were not taking drugs known to interfere with neuromuscular transmission. All patients received glycopyrrolate $0.2 \mathrm{mg}$ intramuscularly as premedication.

The patients were assigned randomly to receive either succinylcholine (control group) or ORG NC45. Patients in the control group were anaesthetized with a standard technique: they received fentanyl $50 \mu \mathrm{g}$ and droperidol $0.5 \mathrm{mg}$, and d-tubocurarine $3 \mathrm{mg}$ and anaesthesia was induced 3 minutes later with thiopentone $3-5 \mathrm{mg} / \mathrm{kg}$.

The patients in the study group were treated similarly except that they received $1 \mathrm{ml}$ of normal saline instead of pre-curarization.

Following induction, anaesthesia was maintained with 70 per cent nitrous oxide in oxygen, supplemented with enflurane $0.5-1.0$ per cent, inspired.

Neuromuscular function was assessed using a
Dupaco peripheral nerve stimulator, supplying a supramaximal stimulus to the ulnar nerve via cutaneous electrodes at the wrist. Trains-of-four stimuli were applied, approximately every 10 seconds, and the thumb twitch was observed. ${ }^{8}$

Patients received neuromuscular blocking agents as shown in Table I. Ventilation was assisted and then controlled until there was complete twitch suppression, when intubation was attempted and the conditions scored after the method of Fahey et $a .^{3}$ (Table II). After intubation, ventilation was controlled using a Ventimeter ventilator and Tpiece, adjusted to maintain normocarbia ${ }^{9}$ Heart rate, blood pressure and electrocardiogram were monitored throughout.

At the end of surgery, an assessment was made of the degree of residual neuromuscular blockade; enflurane was discontinued and either the succinylcholine infusion stopped or the ORG NC45 antagonized with atropine $17 \mu \mathrm{g} / \mathrm{kg}$ and neostigmine $36 \mu \mathrm{g} / \mathrm{kg}$.

Patients were extubated when clinically appropriate, and the time to sustained head lift to command was recorded. If indicated clinically a repeat dose of atropine and neostigmine was administered to patients in the study group.

Mean values are presented with the standard error of the mean as the index of dispersion. Student' $s$ " test for unpaired data was applied where appropriate and the null hypothesis was rejected when $p<0.05$.

\section{Results}

The two groups of patients were comparable with respect to age, weight and duration of anaesthesia (Table I).

\section{Onset of relaxation}

Succinylcholine produced a significantly more rapid onset of neuromuscular block $(p<0.01)$ but 
TABLE [I] Neuromuscular blockade and intubating conditions

\begin{tabular}{|c|c|c|c|c|}
\hline & \multicolumn{3}{|c|}{ Intubation } & \multirow{3}{*}{$\begin{array}{l}\text { Twitch depression } \\
\text { \% }\end{array}$} \\
\hline & \multirow{2}{*}{$\begin{array}{l}\text { Time } \\
\text { sec }\end{array}$} & \multicolumn{2}{|c|}{ Score } & \\
\hline & & $0-1$ & $2-3$ & \\
\hline Succinylcholine & $\begin{array}{r}129.8 \\
+14.2\end{array}$ & (19) & (1) & $\begin{array}{rr}100 & (17) \\
90 & (3)\end{array}$ \\
\hline ORG NC45 & $\begin{array}{r}229.9 \\
\pm 10.8\end{array}$ & (18) & (2) & $\begin{array}{rr}100 & (19) \\
80 & (1)\end{array}$ \\
\hline
\end{tabular}

(Number of patients in parentheses).

Intubation was achieved more rapidly after succinylcholine $(p<0,01)$ but there was no difference in the intubating conditions or degree of neuromuscular block.

the intensity of the block, with the doses used, was similar in both groups (Table III). Consequently, intubating conditions were comparable (Table III) although intubation was achieved at a mean time of $129.8 \pm 14.2 \mathrm{sec}$ after succinylcholine compared with $229.9 \pm 10.8$ sec after ORG NC45.

\section{Maintenance of relaxation}

Muscle relaxation was maintained in the succinylcholine group with an infusion, mean total dose $216.6 \pm 11.4 \mathrm{mg}$. In the ORG NC45 group 4 patients received an additional bolus of $10 \mu \mathrm{g} / \mathrm{kg}$. No additional relaxant was required in the remaining 16 patients.

\section{Recovery from neuromuscular block}

The mean time from administration of ORG NC45 to its antagonism was $28.8 \pm 2.7 \mathrm{~min}$, when little spontaneous recovery of neuromuscular function had occurred: there were no visible twitches in six patients and the block was judged to be at least 90 per cent in 13 others. Responses to all four stimuli in the train (block $<80$ per cent) were seen in only one patient. Two patients received a second dose of atropine and neostigmine and one received naloxone. Recovery in the other patients was uneventful. Spontaneous respiration was restored within five minutes of stopping the succinylcholine infusion or administering neostigmine and sustained head lift was achieved within ten minutes of the last dose of neostigmine.

\section{Discussion}

An ideal muscle relaxant for short operations should produce a rapid onset of intense paralysis which recovers, either spontaneously or after anticholinesterase, after about 30 minutes. There should be minimal or no cardiovascular or other major organ system alterations. Only succinylcholine, of the drugs currently available, has an onset of action of less than 2 min but it has several side effects ${ }^{5}$ and repeated doses, with the risk of phase II block, are required to produce intense paralysis for more than ten minutes. The non-depolarizing relaxants, dtubocurarine, pancuronium and gallamine, have slow onset times ( $>3 \mathrm{~min}$ ) and doses which provide intense blockade have a long duration of action which may be difficult to antagonize with anticholinesterases. ${ }^{10}$ In part, the potency and reversibility can be improved with the addition of the inhalational anaesthetics, isoflurane and enflurane. " However, all these competitive relaxants are associated with cardiovascular effects.

Several neuromuscular blocking drugs, of which ORG NC45 is one, have been developed to avoid these problems. ORG NC45 is more potent than the current drugs, has a rapid rate of spontaneous recovery and is devoid of cardiovascular or other major organ disturbances and appears to be without serious side effects. ${ }^{1-3}$ The rapid rate of spontaneous recovery and easy reversibility suggest that it would be an ideal agent for short operative procedures. Therefore, comparisons with succinylcholine and other short-acting relaxants are more appropriate in determining its clinical role than studies comparing it with other non-depolarizing relaxants. Surprisingly, such a direct comparison has not been reported previously.

The present study has shown that, in comparison with succinylcholine, ORG NC45 in an initial dose of $100 \mu \mathrm{g} / \mathrm{kg}$ produces intense neuromuscular blockade which is easily reversible with neostigmine so that operating conditions and postoperative recovery of neuromuscular function were indistinguishable between the two relaxants. The large dose of ORG NC45 was chosen in an attempt to produce a rapid onset of action but this was not achieved and patients were not intubated until nearly four minutes after its administration. Thus, the onset of neuromuscular blockade seems to be little quicker after ORG NC45 than after pancuronium or d-tubocurarine. Anaesthesia was supplemented with enflurane to potentiate the neuromuscular blocking effect and to aid recovery of neuromuscular activity when it was discontinued. " Neostigmine produced 
rapid recovery although repeated doses were necessary in two patients. Perhaps recovery would be enhanced by a larger initial dose of neostigmine ${ }^{12}$ or edrophonium. ${ }^{13}$ At the time of reversal there was intense neuromuscular blockade in all patients so that monitoring of neuromuscular function to ensure adequate recovery seems to be mandatory. However, it is interesting that six patients made rapid recovery after neostigmine despite total neuromuscular blockade when it was given. It seems that irreversible neuromuscular blockade is an unlikely sequel when the drug is administered in this manner.

In conclusion, ORG NC45 meets some but not all the criteria for a neuromuscular blocking drug for short procedures. In a dose of $100 \mu \mathrm{g} / \mathrm{kg}$ it produces intense neuromuscular blockade which can be antagonized after $\mathbf{3 0}$ minutes. However, the onset of action is slow and care is required to titrate anticholinesterases to ensure adequate recovery.

\section{References}

1 Crul JF, Booij LHD. First clinical experiences with ORG NC 45. Br J Anaesth 1980; 52: 49-52S.

2 Agoston S, Salt P, Newton A, Bencini P, Boomsma $P$, Erdmann $W$. The neuromuscular blocking action of ORG NC 45, a new pancuronium derivative, in anaesthetized patients. Br J Anaesth 1980; 52: $53-9$ S.

3 Fahey MR, Morris RB, Miller RD, Sohn YJ, Cronnelly $R$, Gencarelli $P$. Clinical pharmacology of ORG NC4S (Norcuron): a new non-depolarizing muscle relaxant. Anesthesiology 1981; 55: 6-11.

4 Booij LHDJ, Edwards RP, Sohn YJ, Miller RD. Cardiovascular and neuromuscular effects of ORG NC45, pancuronium, metocurine, and d-tubocurarine in dogs. Anesth Analg 1980; 59: 26-30.

5 Durant NN. Kazz RL. Suxamethonium. Br J Anaesth 1982; 54: 195-208.

6 Harrison $P$, Feldman $S A$. Intubating conditions with ORG NC 45. Anaesthesia 1981; 36: 874-7.

7 Williams A, Gyasi H, Melloni C, Bevan DR. Clinical experience with ORG NC45 (Norcuron) as the sole muscle relaxant. Can Anaesth Soc J 1982; 29: $567-72$

8 Lee C. Train-of-4 quantitation of competitive neuromuscular block. Anesth Analg 1975; 54: 649-53.
9 Bain JA, Spoerel WE. Flow requirements for a modified Mapleson D system during controlled ventilation. Can Anaesth Soc J 1980; 20: 629-36.

10 Lee $C$, Katz RL. Neuromuscular pharmacology. A clinical update and commentary. Br J Anaesth 1980; 52: 173-88.

11 Gencarelli PJ, Miller RD, Eger El, Newfield P. Decreasing enflurane concentrations and d-tubocurarine teuromuscular blockade. Anesthesiology 1982; 56: $192-4$

12 Ferguson A, Egerszegi $P$, Bevan $D R$. Neostigmine, pyridostigmine, and edrophonium as antagonists of pancuronium. Anesthesiology 1980; 53: 390-4.

13 Baird WLM, Bowman WC, Kerr WJ. Some actions of ORG NC45 and of edrophonium in the anaesthetized cat and in man. Br J Anaesth 1982; 54: $375-85$.

\section{Résumé}

On a comparé l'action de l'ORG NC45 et de la succinylcholine en observant la relaxation des muscles chez 40 patients sur lesquels on a pratiqué de peites interventions chirurgicale intra-abdominales avec les agents d'anesthésie protoxide d'azole-oxygène-enfiurane. Les conditions d'intubation avec l'ORG NC45 (100 $\mu \mathrm{g} / \mathrm{kg}$ ) sont similaires à celles de la succinylcholine (I mg/kg), quoique les conditions présenterent la moyenne de $229.9 \pm 10.8$, comparé à $129.8 \pm 10.8$ secondes après l'administration de succinylcholine. La relaxation des muscles pendant l'intervention chirurgicale, en moyenne 32.5 minutes, fut achevée chez le groupe recevant la succinylcholine pur infusion et chez le groupe recevant l'ORG NC4S par des doses bolus $(10 \mu g / k g)$ répétées, qui furent nécessaires chez 4 patients. A la fin de l'intervention chirurgicale, IOORG NC45 a été renversé au moyen d'atropine, $17 \mu \mathrm{g} / \mathrm{kg}$, et de néostigmine, $36 \mu g / k g$ qui furent répétées chez deux patients. La récupération post-opératoire de la fonction neuro-musculaire fut identique chez les deux groupes. Nous concluons donc que l'ORG NC45 est un agent acceptable pour de petites intenentions chirurgicales intra-abdominales si on alloke suffisamment de temps pour produire de bonnes conditions d'intubation. 